\title{
WATER MANAGEMENT AT NORTH SHARKIA IRRIGATION DIRECTORATE
}

Osama K. Saleh, Magdy H. Mowafy, Mohamed O. Elsayed

\begin{abstract}
Egypt is the gift of the Nile, Its destination has been always linked to enhancing the utilization of its water. beginning of perennial irrigation in the middle of nineteenth century until the construction of the Awan higl concern was directed towards better control of the River Nile water. After the construction of the high dam control water resources, the interest directed towards controlling the demand and increasing the efficiency and crop production by the unit of water in Egypt. The purpose of this research is to manage the irrigation demand for all water resources in the study area. The selected study area is located in Awlad Sakr district Governorate. Water quantity is considered during the water managements process. The research provides to reduce the gap between demand and supply by managing water abstraction along the branch canals. $\mathrm{Di}$ approaches of storage water are applied during this research in order to overcome the shortage of water a the main canal and its branches. Different scenarios are introduced and simulate the flow in the canal usin simulation model which is a one dimensional model. SOBEK program is a full hydrodynamic simulator for $r$ and levels in open channels. Four different cases of water storage are suggested. The results have been ar each case. The applied scenarios represent different storage cases for Dafan Canal (case $16.7 \%$, case 25 $33.3 \%$ and case $40 \%$ ) and the results are the water levels, velocities, discharges which were studied for The summarizing the results of this study indicates SOBEK program is a good tool to estimate the hydrauli characteristics in open channel under different scenarios. another result that the case $16.7 \%$ storage is the $25 \%$ storage, the banks in some location need to be raised, while with $33.3 \%$ and $40 \%$ there is shortage c some locations along the canal
\end{abstract}

